\title{
Prevalence of Sleep Bruxism and Association with Oral Health Conditions in Schoolchildren in a Municipality in Southern Brazil
}

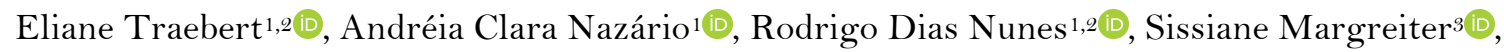 \\ Keila Cristina Raush Pereira ${ }^{4}\left[\right.$, Simone Xavier Silva Costa ${ }^{4}\left(\mathbb{D}\right.$, Jefferson Traebert ${ }^{1,2}(\mathbb{D}$
}

\begin{abstract}
${ }^{1}$ Post-Graduate Program in Health Sciences, University of Southern Santa Catarina, Palhoça, SC, Brazil.
${ }^{2}$ School of Medicine, University of Southern Santa Catarina, Palhoça, SC, Brazil.

${ }^{3}$ Prefecture of Palhoça, Palhoça, SC, Brazil.

${ }^{4}$ School of Dentistry, University of Southern Santa Catarina, Palhoça, SC, Brazil.
\end{abstract}

Author to whom correspondence should be addressed: Eliane Traebert, Avenida Pedra Branca, 25, Cidade Universitária, Pedra Branca, Palhoça, SC, Brazil.88132-270. Phone: +55 4832671167. E-mail: elisazevedot@gmail.com.

Academic Editor: Alessandro Leite Cavalcanti

Received: 10 February 2020 / Accepted: 10 June 2020 / Published: 06 July 2020

How to cite this article: Traebert E, Nazário AC, Nunes RD, Margreiter S, Pereira KCR, Costa SXS, et al. Prevalence of sleep bruxism and association with oral health conditions in schoolchildren in a municipality in Southern Brazil. Pesqui Bras Odontopediatria Clín Integr. 2020; 20:e0019. https://doi.org/10.1590/pboci.2020.125

\footnotetext{
Abstract

Objective: To estimate the prevalence of sleep bruxism and its association with oral health conditions in schoolchildren. Material and Methods: Cross-sectional study carried out in public schools of Tubarão, SC, Brazil with students aged 10 to 15 years. The oral examination was performed in classrooms by dental surgeons, using the WHO criteria. Data on malocclusions, caries and dental trauma, fluorosis, bleeding gums and the presence of dental calculus were collected. For the diagnosis of bruxism, the criterion of the American Academy of Sleep Medicine was adopted. The chi-square test was used to assess the association between sleep bruxism and oral health conditions. Prevalence ratios and confidence intervals were estimated by Poisson regression with robust estimator. Results: A total of 389 students were examined. The prevalence of sleep bruxism was $22.0 \%$. Schoolchildren with malocclusion, increased overjet and dental calculus showed a statistically higher and independent prevalence of $9.0 \%(\mathrm{p}=0.003), 6.0 \%(\mathrm{p}=0.006)$ and $19.0 \%(\mathrm{p}<0.001)$, respectively. Conclusion: Prevalence of sleep bruxism was $22 \%$ in the study population and was associated with malocclusions, particularly increased overjet, and the presence of dental calculus.

Keywords: Parasomnias; Oral Health; Children; Epidemiology.
} 


\section{Introduction}

Bruxism has been studied but questioning about its complex etiology still exists. A systematic review indicated only four studies on the prevalence of bruxism and concluded that more population-based studies were needed [1].

The definition and classification of bruxism is a consensus among researchers [2,3] who agree to define it as a parafunctional action of grinding or clenching the teeth, which can result in the imbalance of different facial structures. It is classified as primary or secondary. The primary form appears to be a persistent chronic disorder, which progresses from childhood or adolescence to adulthood. The secondary form is associated with clinical disorders and with sleep disorders [4,5]. Night bruxism or sleep bruxism, which can also occur in daytime sleep, is detected by children and adolescents' parents when they perceive the noise that their children make with their teeth while they sleep. This has been the most reliable method to diagnose sleep bruxism in children, in addition to clinical characteristics, such as facets of teeth wear [4]. Once the disorder has been diagnosed, the potential etiological factors are investigated in order to define the treatment [4].

Another systematic review showed a greater prevalence of bruxism in children and adolescents than in adults [6]. In fact, population studies have shown this difference in Brazil. A recent study with a representative sample of the population aged 18 years or older in the city of Rio Grande, Brazil, showed 8.1\% prevalence of sleep bruxism. Dental wear and pain in the masticatory muscles were the most reported signs and symptoms [7]. On the other hand, a study involving 440 children aged 8 to 10 years in Diamantina, Brazil, pointed out a prevalence of probable sleep bruxism of $40 \%$, with greater occurrence in children with onychophagia and who usually bite objects [8]. Over the years, studies have shown that sleep bruxism is associated with stress, emotional problems, sleep disorders and other potential causes [4,5,9]. Currently, it is known that bruxism is a movement disorder related to sleep, which involves complex multi-systemic physiological processes [10] and multifactorial etiology yet to be determined. It is thought that bruxism has the potential to interfere with children's quality of life, since a systematic review on the subject included only three studies [11].

In view of the uncertainty of the etiology and factors associated with sleep bruxism [12] the clinical conduct may vary from being only observational and non-interventionist, to requiring multidisciplinary involvement. Although knowledge about sleep bruxism is expanding, a recently published systematic review shows that the factors associated with bruxism and its effects on the structures of the stomatognathic system are considerably heterogeneous and inconsistent [6]. Thus, there is a gap in scientific knowledge in Brazil, about the possible relationship between the occurrence of sleep bruxism and oral health conditions, which constitutes the central issue of the present study.

The objective of this study was to estimate the prevalence of sleep bruxism and its association with oral health conditions in children and adolescents.

\section{Material and Methods}

\section{Study Design}

An epidemiological cross-sectional study was carried out in the municipality of Tubarão, Santa Catarina State, involving public school children and adolescents aged 10 to 15 years.

\section{Sampling}

To calculate the sample size, the following parameters were used: study population composed of 6,554 students who were registered in school during this study, $95 \%$ confidence level, $5 \%$ relative error, unknown 
outcome prevalence in the studied municipality (assigned 50\%, which yields the largest sample size). The estimated participants' number was 363, of which $20 \%$ were added to compensate for potential losses; hence, the final sample resulted in 435 participants. Students were randomly selected, proportionally to the number of students enrolled in the 73 small, medium and large public schools of elementary education. School size was determined through the tertilic distribution of the number of students. First the schools were grouped according to their size and then those that would participate in the survey were randomly selected $(\mathrm{n}=20)$. Afterwards, the students were drawn using a list provided by the registration office of the school.

\section{Data Collection}

The mouth examination was carried out during four consecutive weeks in the classroom, by a team composed of four dentists and four note takers. The team was trained and calibrated [13] prior to the data collection itself, and their kappa values were greater than 0.7 in intra- and inter-examiner exams. The pilot study was carried out with 45 students not belonging to the main study whose objective was to test the proposed methodology. There was no need to make adjustments.

Data on malocclusion were collected using the Dental Aesthetic Index as well as overjet, diastema, crowding and spacing components [14], dental caries [14], dental trauma (O'Brien criteria) [15], fluorosis (Dean's index) [14], gingival bleeding and the presence of dental calculus [14]. For the diagnosis of sleep bruxism, the criteria established by the American Academy of Sleep Medicine (AASM) [16] were adopted. Data were collected from reports of teeth grinding or teeth clenching during sleep, associated with abnormal tooth wear, discomfort in the TMJ or in the masticatory muscles. Regarding the wear facets, only the anterior teeth were considered to diagnose sleep bruxism. Non-clinical data were collected through a questionnaire sent to parents or guardians, with questions about sleep bruxism (AASM), age and gender of the student.

\section{Data Analysis}

The data collected were entered into an Excel spreadsheet and exported to the SPSS 18.0 software for statistical analysis. The descriptive analysis was performed based on the prevalence of sleep bruxism distributed by gender (male; female), age (categorized in the distribution median), presence of dental caries, dental trauma, malocclusion, overjet, diastema, crowding and tooth spacing, fluorosis, gingival bleeding and dental calculus (all categorized as yes and no). The Chi-square test was used to measure the association between sleep bruxism and the variables studied. Prevalence ratios (PR) and their relevant confidence intervals $(95 \%)$ were estimated by Poisson regression with a robust estimator, including all variables with $\mathrm{p}<0.20$ in the bivariate analysis. Two models were developed. The first one to study the association between the prevalence of sleep bruxism and different oral health conditions, including gender and age. The second model aimed to test the association between sleep bruxism and the components of the DAI, maintaining the associations with the other oral conditions. The level of significance established in the final models was $\mathrm{p}<0.05$.

\section{Ethical Aspects}

This study was submitted to and approved by the Research Ethics Committee of the University of the South of Santa Catarina under Consubstantiated Opinion number 11.142.4.02.III. All parents or guardians who agreed to participate in the investigation signed a free and informed consent form.

\section{Results}


A total of 389 students were examined, which generated a response rate of $89.4 \%$ against the calculated sample. Out of these, $59.6 \%$ were female and $67.4 \%$ were between 10 and 12 years of age.

The prevalence of sleep bruxism was $22.0 \%$ (95\% CI 17.9; 26.1). Dental caries were observed in $44.5 \%$ (95\% CI 39.6; 49.4) schoolchildren; dental trauma in $7.2 \%$ (95\% CI 4.7; 9.7); malocclusion in $84.8 \%$ (95\% CI 81.3; 88.3); gum bleeding in 4.9\% (95\% CI 2.8; 7.0) and $11.8 \%$ (95\% CI 8.6; 15.0) presented with dental calculus. The prevalence of sleep bruxism was associated with dental caries $(\mathrm{p}=0.005)$, presence of malocclusion $(\mathrm{DAI})$ $(\mathrm{p}<0.001)$, overjet $>3 \mathrm{~mm}(\mathrm{p}<0.001)$, dental crowding $(\mathrm{p}=0.050)$, fluorosis $(\mathrm{p}=0.016)$ and dental calculus $(\mathrm{p}<0.001)$ (Table 1).

Table 1. Distribution of the studied variables.

\begin{tabular}{|c|c|c|c|}
\hline \multirow[b]{2}{*}{ Variables } & \multicolumn{2}{|c|}{ Sleep Bruxism } & \multirow[b]{2}{*}{ p-value } \\
\hline & $\begin{array}{c}\text { Yes } \\
\text { N (\%) }\end{array}$ & $\begin{array}{c}\text { No } \\
\text { N (\%) }\end{array}$ & \\
\hline \multicolumn{4}{|l|}{ Gender } \\
\hline Male & $21(13.4)$ & $136(86.6)$ & 0.149 \\
\hline Female & $20(8.6)$ & $212(91.4)$ & \\
\hline \multicolumn{4}{|l|}{ Age (Years) } \\
\hline Up to 12 & $28(10.7)$ & $234(89.3)$ & 0.891 \\
\hline Above 12 & $13(10.2)$ & $114(89.8)$ & \\
\hline \multicolumn{4}{|l|}{ Dental Caries } \\
\hline No & $14(6.5)$ & $202(93.5)$ & 0.005 \\
\hline Yes & $27(15.6)$ & $146(84.4)$ & \\
\hline \multicolumn{4}{|l|}{ Dental Trauma } \\
\hline No & $37(10.2)$ & $324(89.8)$ & 0.557 \\
\hline Yes & $4(14.3)$ & $24(85.7)$ & \\
\hline \multicolumn{4}{|l|}{ Malocclusion (DAI) } \\
\hline No & $4(2.4)$ & $162(97.6)$ & $<0.001$ \\
\hline Yes & $37(16.6)$ & $186(83.4)$ & \\
\hline \multicolumn{4}{|l|}{ Overjet $>3 \mathrm{~mm}$} \\
\hline No & $10(4.7)$ & $202(95.3)$ & $<0.001$ \\
\hline Yes & $31(17.5)$ & $146(82.5)$ & \\
\hline \multicolumn{4}{|l|}{ Diastema } \\
\hline No & $30(9.0)$ & $304(91.0)$ & 0.056 \\
\hline Yes & $11(20.0)$ & $44(80.0)$ & \\
\hline \multicolumn{4}{|l|}{ Dental Crowding } \\
\hline No & $17(7.8)$ & $202(92.2)$ & 0.050 \\
\hline Yes & $24(14.1)$ & $146(85.9)$ & \\
\hline \multicolumn{4}{|l|}{ Dental Spacing } \\
\hline No & $26(8.6)$ & $276(91.4)$ & 0.052 \\
\hline Yes & $15(17.2)$ & $72(82.8)$ & \\
\hline \multicolumn{4}{|l|}{ Fluorosis } \\
\hline No & $27(8.3)$ & $297(91.7)$ & 0.016 \\
\hline Yes & $14(21.5)$ & $51(78.5)$ & \\
\hline \multicolumn{4}{|l|}{ Gengival Bleeding } \\
\hline No & $38(10.3)$ & $332(89.7)$ & 0.523 \\
\hline Yes & $3(15.8)$ & $16(84.2)$ & \\
\hline \multicolumn{4}{|l|}{ Dental Calculus } \\
\hline No & $23(6.7)$ & $320(93.3)$ & $<0.001$ \\
\hline Yes & $18(39.1)$ & $28(60.9)$ & \\
\hline
\end{tabular}


Table 2 shows the results of the multivariate analysis between the prevalence of sleep bruxism and the variables related to oral conditions. It was observed that the prevalence of bruxism was $9 \%$ greater and independently in children who presented with malocclusion $(\mathrm{PR}=1.09 ; 95 \% \mathrm{CI} 1.02 ; 1.08 ; \mathrm{p}=0.003)$ and $18 \%$ greater and independently in children with dental calculus $(\mathrm{PR}=1.18 ; 95 \% \mathrm{CI} 1.08 ; 1.28 ; \mathrm{p}<0.001)$.

Table 2. Poisson regression results for prevalence of sleep bruxism and oral health conditions.

\begin{tabular}{|c|c|c|c|c|}
\hline Variables & PR. $(95 \%$ CI $)$ & p-value & $\mathrm{PR}_{\mathrm{a}}(95 \% \mathrm{CI})$ & p-value \\
\hline \multicolumn{5}{|l|}{ Gender } \\
\hline Male & 1.00 & 0.149 & 1.00 & 0.359 \\
\hline Female & $1.02(0.99-1.06)$ & & $1.02(0.98-1.05)$ & \\
\hline \multicolumn{5}{|l|}{ Age (Years) } \\
\hline Up to 12 & 1.00 & 0.891 & \# & \\
\hline Above 12 & $1.00(0.97-1.04)$ & & & \\
\hline \multicolumn{5}{|l|}{ Dental Caries } \\
\hline No & 1.00 & 0.005 & 1.00 & 0.071 \\
\hline Yes & $1.05(1.01-1.09)$ & & $1.03(0.99-1.06)$ & \\
\hline \multicolumn{5}{|l|}{ Dental Trauma } \\
\hline No & 1.00 & 0.557 & \# & \\
\hline Yes & $0.99(0.91-1.05)$ & & & \\
\hline \multicolumn{5}{|l|}{ Malocclusion (DAI) } \\
\hline No & 1.00 & $<0.001$ & 1.00 & 0.003 \\
\hline Yes & $1.08(1.05-1.11)$ & & $1.09(1.02-1.08)$ & \\
\hline \multicolumn{5}{|l|}{ Fluorosis } \\
\hline No & 1.00 & 0.016 & 1.00 & 0.672 \\
\hline Yes & $1.07(1.01-1.14)$ & & $1.01(0.95-1.08)$ & \\
\hline \multicolumn{5}{|l|}{ Gengival Bleeding } \\
\hline No & 1.00 & 0.523 & \# & \\
\hline Yes & $1.03(0.94-1.13)$ & & & \\
\hline \multicolumn{5}{|l|}{ Dental Calculus } \\
\hline No & 1.00 & $<0.001$ & 1.00 & $<0.001$ \\
\hline Yes & $1.20(1.10-1.31)$ & & $1.18(1.08-1.28)$ & \\
\hline
\end{tabular}

Table 3 shows a model in which the statistically significant variables remained, but with details of the DAI components. It was possible to verify that the prevalence of sleep bruxism was $6 \%$ greater and independently in students who presented with overjet $>3 \mathrm{~mm}(\mathrm{PR}=1.06 ; 1.02-1.11 ; \mathrm{p}=0.006)$ and $19 \%$ greater and independently in students with dental calculus $(\mathrm{PR}=1.19 ; 1.09-1.30 ; \mathrm{p}<0.001)$.

Table 3. Poisson regression results for the prevalence of sleep bruxism and types of malocclusion and dental calculus.

\begin{tabular}{|c|c|c|c|c|}
\hline Variables & PR. $(95 \%$ CI $)$ & p-value & $\mathrm{PR}_{\mathrm{a}}(95 \% \mathrm{CI})$ & p-value \\
\hline \multicolumn{5}{|l|}{ Gender } \\
\hline Male & 1.00 & 0.149 & 1.00 & 0.443 \\
\hline Female & $1.02(0.99-1.06)$ & & $1.01(0.98-1.04)$ & \\
\hline \multicolumn{5}{|l|}{ Overjet $>3 \mathrm{~mm}$} \\
\hline No & 1.00 & $<0.001$ & 1.00 & 0.006 \\
\hline Yes & $1.07(1.03-1.11)$ & & $1.06(1.02-1.11)$ & \\
\hline \multicolumn{5}{|l|}{ Diastema } \\
\hline No & 1.00 & 0.056 & 1.00 & 0.397 \\
\hline Yes & $1.06(0.99-1.13)$ & & $1.03(0.96-1.12)$ & \\
\hline
\end{tabular}




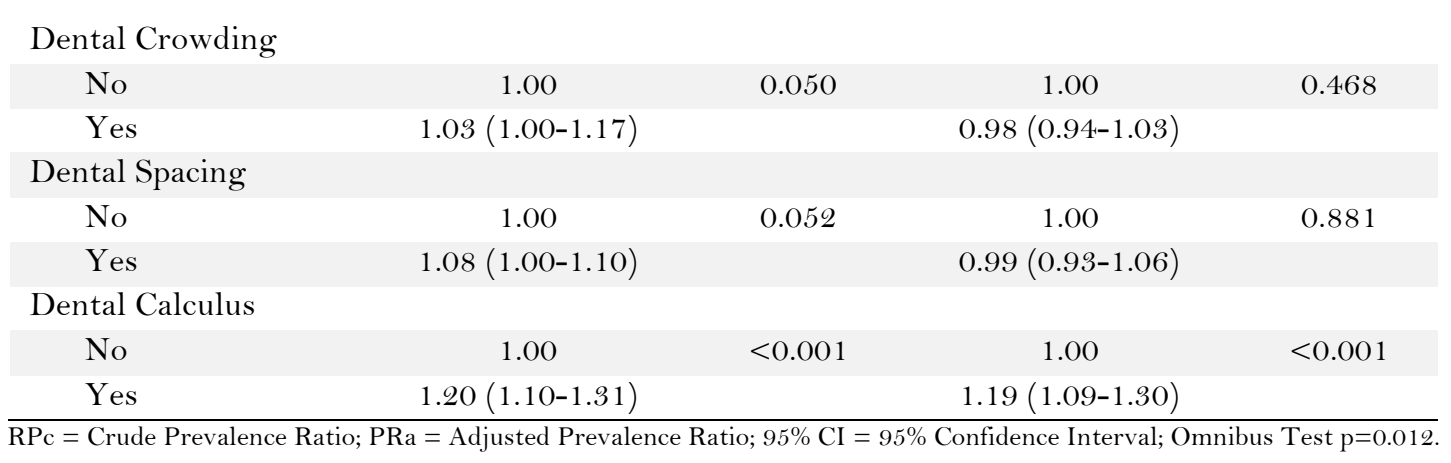

\section{Discussion}

The high response rate of this study and the diagnostic reproducibility achieved in the calibration of the examiners suggest good internal validity.

The prevalence of sleep bruxism in the population studied was $22 \%$ and there was no statistically significant difference between the genders. This relationship was also evidenced in other studies in which there was no difference in the prevalence of bruxism between boys and girls [17,18].

Among the variables assessed, the present study found in the adjusted analysis, that the prevalence of sleep bruxism was greater in children with malocclusion $(\mathrm{p}=0.003)$ and dental calculus $(\mathrm{p}<0.001)$. Among the types of malocclusion assessed using the Dental Aesthetics Index, the prevalence of sleep bruxism was greater in children with overjet $>3 \mathrm{~mm}(\mathrm{p}=0.006)$.

In a literature review, it was sustained that the etiology of bruxism is multifactorial, that is, it is the combination of systemic, local, psychological, occupational and hereditary factors [19]. Among the factors associated with bruxism, are malocclusions, occlusal trauma, presence of dental calculus, missing teeth, excess restorative material and muscle tension [20]. Malocclusions, inadequate restorations, dental calculus, tooth mobility, lip deformities, gingival hyperplasia, in addition to other factors related to occlusal physiology favored the establishment of bruxism [21], corroborating the results of this study.

However, previous authors in order to assess the relationship between bruxism, occlusal factors and oral habits in children and adolescents, attending public schools in the city of Brasília, Brazil, found a statistically significant association with the pacifier sucking habit; however bruxism was not associated to the occlusal factors studied [18], contrary to the results of the present study.

Sleep bruxism in children and adolescents has been considered to have a multifactorial etiology, with the participation of local, systemic, psychological and hereditary factors [22]. Perhaps this is a hypothesis that explains the results of the present study related to associations with malocclusions, more specifically the increased overjet and with the presence of dental calculus. In fact, there is little knowledge about the relationship between sleep bruxism and periodontal conditions, specifically with the presence of dental calculus. However, a significant association between the occurrence of bruxism and bone loss due to periodontal disease was observed [23], thus indicating the plausibility of the association between risk factors for periodontal disease and the occurrence of sleep bruxism. Thus, further studies are needed, since the present work contributes incipiently to the understanding of the potential relationship between oral health conditions and the occurrence of sleep bruxism. There is a need for studies with adequate designs, preferably longitudinal, to elucidate the effects of sleep bruxism on the health conditions of children and the direction of the possible cause-effect relationship between them if any, since the current literature shows an heterogeneous and inconsistent relationship [6]. 
The prevalence found in the present study implies that there is a need for professionals to be prepared to make the diagnosis from the signs and symptoms, both of the event itself, and of the possible relationships with oral health conditions, especially malocclusion and oral hygiene conditions. The greater the dentist's knowledge and the awareness of patients and their families about sleep bruxism, the better the prognosis, since bruxism's etiology is multifactorial [24].

Thus, dental procedures should be performed to preserve dental structures, providing conditions for occlusal balance, important in protecting teeth, relaxing muscles and preventing joint overload. Regardless of the factors involved in sleep bruxism etiology, occlusal therapy may be indicated, as it promotes functional comfort and prevents further damage to the components of the masticatory system, evidencing multiple therapeutic effects on several components of the stomatognathic system [24]. In addition, orthodontic procedures for the correction of malocclusions, especially marked overjet, can benefit sleep bruxism management. Preventive procedures such as prophylaxis and oral health promotion focusing on proper hygiene can help both in sleep bruxism and in oral health as a whole.

The main limitations of this investigation reside in the cross-sectional design of the study, which prevents the establishment of aetiology, including the direction of the association found. That is, the question remains whether sleep bruxism contributes to poor oral health or if poor oral health favors the occurrence of the event. In addition, it should be noted that the sample studied was made up only of children from public schools. The non-inclusion of students from private schools, which in theory, could represent a population stratum of better socioeconomic status and other independent variables related to the child and family, especially mothers, suggests a cautious analysis of the results presented.

\section{Conclusion}

The prevalence of sleep bruxism was $22 \%$ in the population studied and was associated with malocclusions, particularly increased overjet, and the presence of dental calculus.

\section{Authors' Contributions}

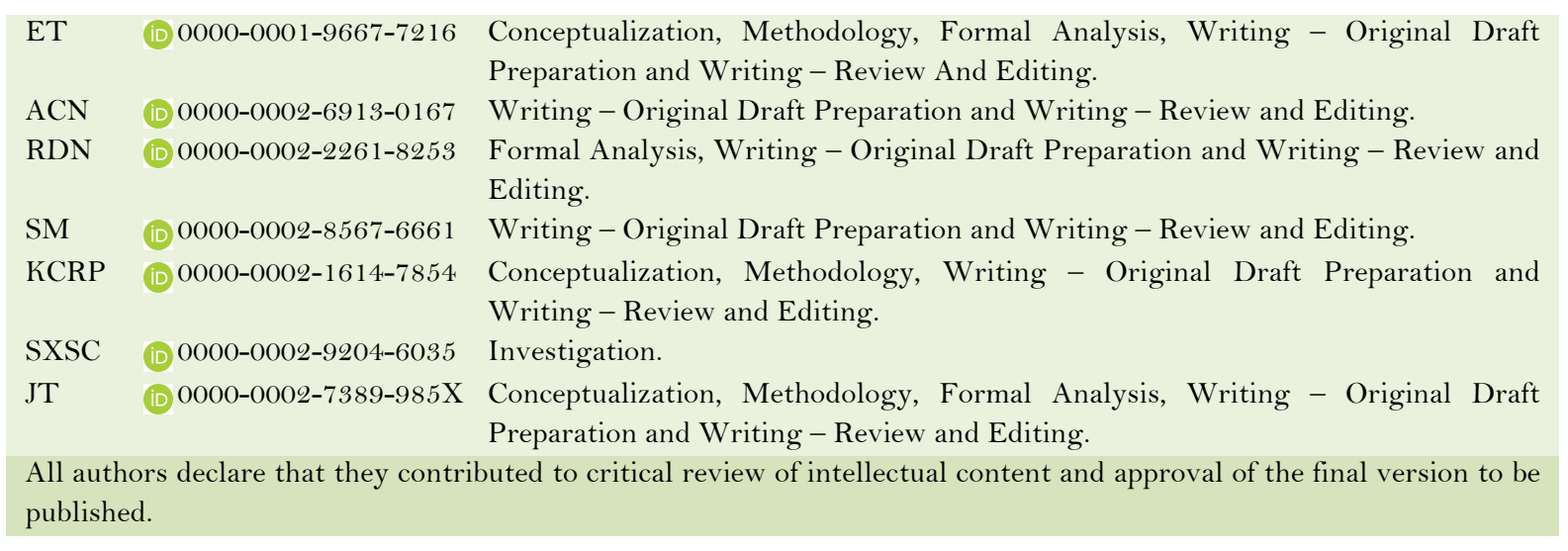

\section{Financial Support}

Fundação de Amparo à Pesquisa e Inovação do Estado de Santa Catarina (Grant 003/2010 PPSUS/SC), Coordenação de Aperfeiçoamento de Pessoal de Nível Superior - Brasil (PROSUC/CAPES) - Finance Code 001.

\section{Conflict of Interest}

The authors declare no conflicts of interest. 


\section{References}

[1] Machado E, Dal-Fabbro C, Cunali PA, Kaizer OB. Prevalence of sleep bruxism in children: a systematic review. Dental Press Orthod 2014; 19(6):54-61. https://doi.org/10.1590/2176-945 1.19.6.054-061.oar

[2] Reddy SV, Kumar MP, Sravanthi D, Mohsin AHB, Anuhya V. Bruxism: a literature review. J Int Oral Health 2014; 6(6):105-9.

[3] Seraidarian PI, Assunção ZLV, Jacob MF. Bruxism: An update of concepts, etiology, prevalence and management. J Bras Oclus ATM Dor Orofac 2001; 1(4):290-5.

[4] Firmani M, Reyes M, Becerra N, Flores G, Weitzman M, Espinosa P. Bruxismo de sueño en niños y adolescentes. Rev Chil Pediatr 2017; 86(5):373-9. https://doi.org/10.1016/j.rchipe.2015.05.001 [In Spanish]

[5] Bader G, Lavigne G. Sleep bruxism: an overview of an oromandibular sleep movement disorder. Sleep Med Rev 2000; 4(1):27-43. https://doi.org/10.1053/smrv.1999.0070

[6] Melo G, Duarte J, Pauletto P, Porporatti AL, Stuginski-Barbosa J, Winocur E, et al. Bruxism: an umbrella review of systematic reviews. J Oral Rehabil 2019; 46(7):666-90. https://doi.org/10.1111/joor.12801

[7] Pontes LS, Prietsch SOM. Sleep bruxism: population-based study in people with 18 years or more in the city of Rio Grande, Brazil. Rev Bras Epidemiol 2019; 22:e190038. https://doi.org/10.1590/1980-549720190038

[8] Drumond CL, Ramos-Jorge J, Vieira-Andrade RG, Paiva SM, Serra-Negra JMC, Ramos-Jorge ML. Prevalence of probable sleep bruxism and associated factors in Brazilian schoolchildren. Int J Paediatr Dent 2019; 29(2):221-7. https://doi.org/10.1111/ipd.12443

[9] Kuhn M, Türp JC. Risk factors for bruxism. Swiss Dent J 2018; 128(2):118-24.

[10] Klasser GD, Rei N, Lavigne GJ. Sleep bruxism etiology: the evolution of a changing paradigm. J Can Dent Assoc 2015; 81:f2.

[11] Rodrigues JA, Azevedo CB, Chami VO, Solano MP, Lenzi TL. Sleep bruxism and oral health-related quality of life in children: a systematic review. Int J Paeditr Dent 2020; 30(2):136-43. https://doi.org/10.1111/ipd.12586

[12] Macedo CR. Bruxismo do sono. Rev Dent Press Ortodon Ortop Facial 2008; 13(2):18-22. https://doi.org/10.1590/S1415-54192008000200002 [In Portuguese]

[13] Peres MA, Traebert J, Marcenes W. Calibration of examiners for dental caries epidemiologic studies. Cad Saude Publica 2001; 17(1):153-9. https://doi.org/10.1590/So102-311X2001000100016

[14] World Health Organization. Oral Health Surveys: Basic Methods. Geneva: World Health Organization; 1997

[15] O'Brien M. Children's dental health in United Kingdom 1993. Office of population censuses and surveys. London: Her Majesty's Stationery Office; 1994.

[16] American Academy of Sleep Medicine. International Classification of Sleep Disorders. 3rd. ed. Darien: American Academy of Sleep Medicine; 2014.

[17] Emodi-Perlman A, Eli I, Friedman-Rubin P, Goldsmith C, Reiter S, Winocur E. Bruxism, oral parafunctions, anamnestic and clinical findings of temporomandibular disorders in children. J Oral Rehabil 2012; 39(2):126-35. https://doi.org/10.1111/j.1365-2842.2011.02254.x

[18] Gonçalves LPV, Toledo OA, Otero SAM. The relationship between bruxism, occlusal factors and oral habits. Dental Press J Orthod 2010; 15(2):97-104. https://doi.org/10.1590/S2176-94512010000200013

[19] Simões-Zenari M, Bitar ML. Factors associated to bruxism in children from 4 - 6 years. Pró-Fono Rev Atual Cient 2010; 22(4):465-72. https://doi.org/10.1590/So104-56872010000400018

[20] Diniz MB, Silva RC, Zuanon ACC. Childhood bruxism: a warning sign to pediatric dentists and pediatricians. Rev Paul Pediatr 2009; 27(3):329-34. https://doi.org/10.1590/S0103-05822009000300015

[21] Alves AC, Alchieri JC, Barbosa GAS. Bruxism. Masticatory implications and anxiety. Acta Odontol Latinoam 2013; 26(1):15-22.

[22] Moresca RC. Bruxismo em crianças: etiologia e tratamento: revisão da literatura. [Monografia]. Setor de Ciências da Saúde: Universidade Federal do Paraná; 2016. [In Portuguese]

[23] Martinez-Canut P, Llobell A, Romero A. Predictors of long-term outcomes in patients undergoing periodontal maintenance. J Clin Periodontol 2017; 44(6):620-31. https://doi.org/10.1111/jcpe.12730

[24] Gama E, Andrade AO, Campos RM. Bruxism: literature review. Ciência Atual 2013; 1(1):16-22. 